\section{Reclaim your time}

Wouldn't it be great to free up your time to focus on what matters to you? Cloud based software allows you to do just that.

'Cloud' is a word no longer just used by the tech community or just related to the suite of products from Apple, but a term with wider connotations that has changed the way we all live and work. The cloud quietly exists in the background around our software and hardware, sitting somewhere in the 'sub-conscious' of our everyday lives.

We use the cloud more frequently than ever before. It's now such an integral part of our daily life. We use it for storing our treasured images, because gone are the days of remembering to pack the camera - today we snap away with our mobile phones regardless, taking selfies at every moment, countless food pictures and wed lose track of the shots of our friends and families if they were not available from any device! We use the cloud when downloading films or when viewing catch up TV to watch the latest must see box set, for storing our passwords securely or for a simple purchase from Amazon. Whether we realise it or not cloud technology is everywhere; it's accessible, easy to support, faster and more secure.

Cloud technology has already changed the way many people work. No longer do businesses need to ensure that their staff are clocked in and at their desk at $9.00 \mathrm{am}$ and gone by $5 \mathrm{pm}$, with work unfinished or the other extreme where staff are stuck behind their desk until 9 pm doing overtime to get all tasks completed. We are now in a world where we understand that teams can be more productive and efficient

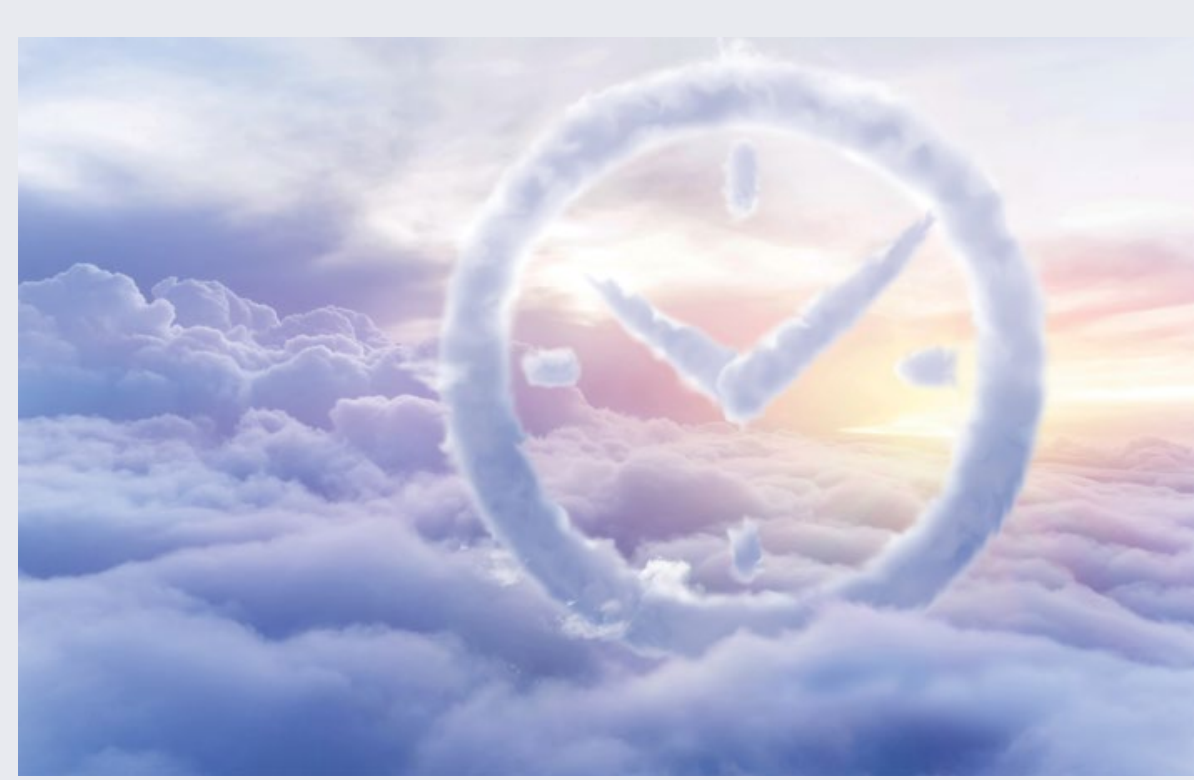

by being more flexible in the way they work - offering people a much more enjoyable work-life balance.

For the world of dentistry it is equally transformative, allowing dentists to see patients during surgery hours and then head home as the last patient leaves the practice to spend precious time with family, meet friends or head to the gym. No longer do dental practitioners need to work on finishing patient notes while stuck in the surgery; these can be done later and on their terms - logging in from home when the children are in bed or after dinner with loved ones.

The British Dental Association and the NHS have long been reporting on the growing issues surrounding working hours and in the State of Dentistry Report 2019, similar findings were highlighted with $75 \%$ of dentists working more hours than previously. The challenges of the industry remain but if technology, like cloud-based software can be leveraged, then it certainly assists in establishing a better work-life balance for dentists.

Seventy-six percent of dentists said that being able to work flexibly using technology to carry out admin work away from the office would make them happier. It allows them to focus on their business at a time and place of their choosing without being tied to the practice. Many dentists are still hampered by on-site legacy systems, but with cloud-based technology offering a solution that allows dentists to work from anywhere, rather than working late or coming in early, there is certainly a way forward to discover a work/life balance.

To learn more about Dentally, the UK's leading cloud practice management software, and how you can work smarter and work remotely, simply email hello@ dentally.co for a demo.

To download a copy of the State of Dentistry report 2019 visit https://info. dentally.co/smile-2019.

\title{
The secret that patients will love!
}

Discreet orthodontic lingual appliances are a perfect way to help patients who are concerned that braces could impact their smiles during treatment.

So why not choose one of the most trusted discreet appliances in the industry - the Incognito Appliance System from 3M Oral Care.

Completely custom-made to every individual, this innovative system is placed behind the teeth and remains hidden from

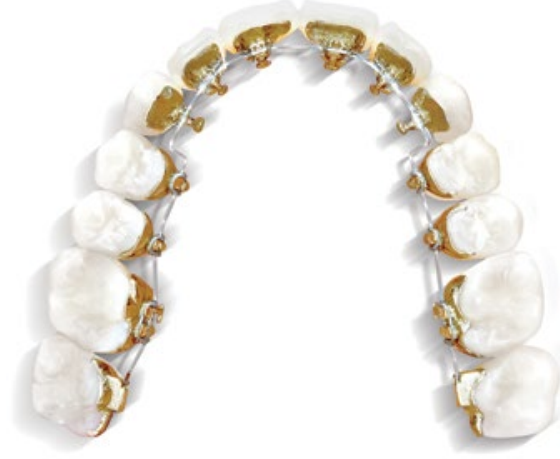

view during treatment. Furthermore, as every part of the Incognito Appliance System is completely bespoke, this ensures that clinicians are able to achieve predictable, controlled outcomes.

For more information, call 0845873 4066 or visit http://solutions.3m.co.uk/wps/ portal/3M/en_GB/orthodontics_EU/Unitek/.

$3 \mathrm{M}$ is a trademark of the $3 \mathrm{M}$ Company. Incognito is a trademark of TOP-Service für Lingualtechnik $\mathrm{GmbH}$. 